\title{
INNOVATIVE BI APPROACHES AND METHODOLOGIES IMPLEMENTING A MULTILEVEL ANALYTics Platform Based on DATa Mining AND ANALYTICAL MODELS: A CASE OF STUDY IN ROADSIDE ASSISTANCE SERVICES
}

\author{
Alessandro Massaro ${ }^{1}$, Angelo Leogrande ${ }^{1}$, Palo Lisco $^{1}$, Angelo Galiano ${ }^{1}$ and Nicola \\ Savino $^{1}$ \\ ${ }^{1}$ Dyrecta Lab, IT Research Laboratory, Via Vescovo Simplicio, 45, 70014 Conversano \\ (BA), Italy. \\ (in collaboration with ACI Global S.p.A., Viale Sarca, 336 - 20126 Milano, Via Stanislao \\ Cannizzaro, 83/a - 00156 Roma, Italy)
}

\begin{abstract}
The paper proposes an advanced Multilevel Analytics Model-MAM-, applied on a specific case of study referring to a research project involving an industry mainly working in roadside assistance service (ACI Global S.p.A.). In the first part of the paper are described the initial specifications of the research project by addressing the study on information system architectures explaining knowledge gain, decision making and data flow automatism applied on the specific case of study. In the second part of the paper is described in details the MAM acting on different analytics levels, by describing the first analyzer module and the second one involving data mining and analytical model suitable for strategic marketing e business intelligence -BIThe analyzer module is represented by graphical dashboards useful to understand the industry business trend and to execute main decision making. The second module is suitable to understand deeply services trend and clustering by finding possible correlations between the variables to analyze. For the data mining processing has been applied the Rapid Miner workflows of K-Means clustering and the Correlation Matrix. The second part of the paper is mainly focused on analytical models representing phenomena such as vehicle accidents and fleet car sharing trend, which can be correlated with strategic car services. The proposed architectures and models represent methodologies and approaches able to improve strategic marketing and-BI-advanced analytics following 'Frascati' research guidelines. The MAM model can be adopted for other cases of study concerning other industry applications. The originality of the paper is the scientific methodological approach used to interpret and read data, by executing advanced analytical models based on data mining algorithms which can be applied on industry database systems representing knowledge base.
\end{abstract}

\section{KEYWORDS}

Data Mining, K-Means, Correlation Matrix, Analytical Modeling, Frascati Guideline, Rapid Miner.

\section{INTRODUCTION: BI SPECIFICATIONS AND MAM FRAMING}

In this section is reported the state of the art concerning the main specifications of the industry project within has been applied the research approaches and methodologies. Concerning strategic marketing and business intelligence $-\mathrm{BI}-$, the industry cost analysis is relevant. The costs can be classified in [1]:

- Conventionally calculable costs;

- Potentially hidden costs; 
- External costs of the company.

Therefore, the costs represent a starting point of analysis to keep under control. This is possible by adopting an efficient information system able to utilizes automatically the knowledge base -KB-. The cost analysis should follow the logic of the marketing expansion (for example by considering future service costs associated with innovative car technologies such as electric cars and hybrid ones [2]). An aspect of considerable interest for the efficiency of a BI model, is also the social communication [3]. In this context, the social network could also be used in order to analyze marketing trends by validating the outputs of the BI models. Another communication tool that is increasingly useful for companies is mobile marketing [4]. In this direction, it is interesting to analyze the impact of company mobile apps in order to find important input data for analytics. Methodologies and approaches for Business Performance Management-BPM-, can be formulated by performance indicators (key performance indicators -KPIs-), and by reading properly graphical dashboards suitable for the decision making process. The BPM is based on the concept of data integration and is characterized by the following four sub-phases [5]:

1. strategize;

2. plan;

3. monitor;

4. act and adjust.

The BPM model is therefore an advanced $\mathrm{BI}$ requiring information integration and a correct choice of data [6]. The BI is therefore based on information management systems [7], where the highest level of complexity is represented by the data mining. For this purpose data mining algorithms could be adopted for a second advanced level of analysis. Data mining therefore plays a key role in BI decision making [8], which is why the relative outputs will be of greater value when compared to the outputs of the first level of analysis. Other important variables which could play an important role for strategic marketing [9] are:

- company objectives;

- resources and capabilities;

- information system;

- company network;

- information about competitors;

- information about customers;

- updating of government laws.

A concept associable with that of BI is the marketing intelligence -MI- [10]. Recent studies [11] have shown a BI architecture system consisting of several inputs [11], including customer relationship management -CRM- inputs, whose data may be of particular importance for an advanced analytics performed by data mining algorithms [12]. Also the surrounding environment variables [13] and the big data systems [14] could play an important role in BI analytics. Concerning the information integration concept, it is important to design an information system able to integrate multiple information channels [15], and to analyze system errors [16]. Another topic still useful for the analysis is the logistics [17]. Finally, clustering and the classification of accidents [18]-[19] could instead be an alternative approach to understand the need of assistance services. Both clustering and classification can be obtained through specific data mining algorithms such as k-means [20]. The concept of classification could also be extended to the services classification [21]. Following the main specification of the state of the art has been formulated the architecture layout of Fig. 1 representing a model developing BI analytics for a specific case of study. The proposed model is named multilevel analytics model -MAM-, and consists of the following two levels of analysis modeled by two blocks in cascade connection: 
- the first level analysis (level I) represented by the "Analyzer" module: this level allows the input data analysis (display phases, data visualization and graphical interpretation according to the traditional BI analytics model), the data pre-processing, and data normalization (data processing useful for the second level analysis);

- the second level analysis (level II): this level allows the implementation of analytical models, data mining workflows, and data mining algorithms.

The MAM model potentially could provide:

- efficiency indicators processing data of the information systems and of open data systems;

- deeply analysis of results of adopted strategies;

- information about strategic marketing associated with car service industry;

- information about customer behavior, customer segmentation, and customer sentiment [22];

- effect of the environment variables on the BI and on services;

- other information;

Data processes and data systems suitable for the pre-analysis phase of the first level analysis are:

- formulation of procedures oriented on managing the industry activities evaluating their consistency over time (this aspect could direct the BI operations to reduce the services costs by refining prices);

- formulation of processes related the optimization and the standardization of heterogeneous databases thus facilitating customer service analyses (database system integration operation and data process automatism);

- basic reporting for BI analysis;

- customer data processing (useful to have a precise control on the quality of provided services increasing efficiency);

- system able to expresses the ability to promptly identify the most suitable delegate centers to offer a service to the customer as quickly as possible;

- system for the automated management of platforms and data thus allowing the development of related inter-application interfaces;

- Enterprise Content Management -ECM- data system, allowing a quick access to archived practices thus ensuring the ability to historicize and recover all the activities carried out for the customers about the number and the importance of interventions;

- e-commerce data processing useful to analyze additional sales data associated with electronic commerce;

- technology transfer element provided by e-learning facilities able to optimize the knowledge level of the project improvements. 


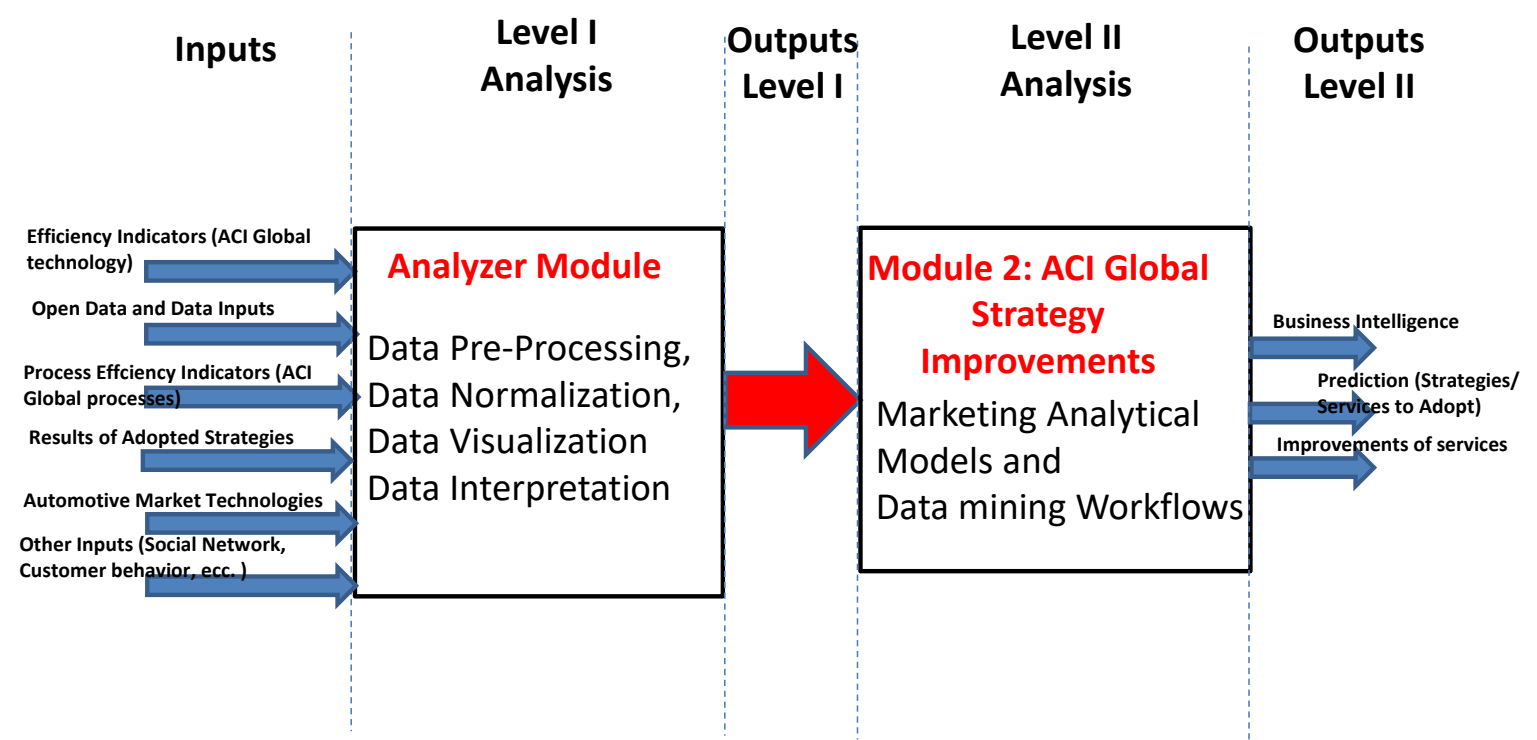

Figure 1. Theoretical Multilevel Analytics Model-MAM-.

In the proposed paper are discussed part of the initial project specifications. In particular the work is structured as follows:

- is described the framework within has been developed the MAM by showing the main system architectures embedding different upgrading information system facilities and the 'Frascati' concepts enabling the research topics;

- are provided some project implementations explaining the knowledge gain concept by showing data process and data automatism about management of service practice,

- $\quad$ are designed and executed MAM for different variables of the integrated database system such as amount clustering, car accidents and fleet sharing.

\section{Frascati R\&D GUIDELINES: MATCHING WITH PROJECT SPECIFICATIONS}

The research activities follow the R\&D guidelines discussed in 'Frascati' manual [23]. According with the scheme of Fig. 2 the MAM architecture of Fig. 1 is located on the level 4 of the knowledge gain (maximum level). The data systems listed in the previous paragraphs concern mainly level 2 and level 3 of the model of Fig.2 and are necessary to improve knowledge gain. By means of information infrastructures such as Enterprise Service Bus -ESB- [24]-[26] it possible to solve conflicts between hardware and software tools and to integrate data coming from different technologies and structured in different formats. In particular data mining algorithms represent "new or more efficient algorithms based on new techniques" ([23] pag. 66: concept of software included in R\&D), besides analytical models of the module 2 mainly represent a basic research improving "relationships with a view to formulating and testing hypotheses" ([23] pag. 50: basic research), and related to the following topics: "Economists conducting abstract research in economic theory that focuses on whether a natural equilibrium exists in a market economy. The development of new risk theories" ([23] pag. 56). The task implemented for a specific R\&D framework are performed by "researchers may be involved fully or partially in different types of activities (e.g. basic or applied research, experimental development, operating research equipment, project management, etc.) in any sector of the economy" ([23] pag. 162), by "developing concepts, theories, models, techniques, instrumentation, software and operational methods", by "gathering, processing, evaluating, analysing, and interpreting research data", by "evaluating the results of investigations and experiments and positing conclusions using different techniques and models", by "applying principles, techniques and processes to develop or improve 
practical applications", by "planning, directing and coordinating the $R \& D$ activities of institutions that provide related services to other organisations" and by "preparing scientific papers and reports" ([23] pag. 162). In order to experiment the new theories and the new models it is important to improve before the knowledge base by implementing different software and data base systems able to provide information and data to process (see level 2 of Fig. 2). In the next paragraphs will be shown some important steps proving the alignment of the implementations with the 'Frascati' R\&D guidelines. The architecture of Fig. 2 is a results of different joint projects developed in ACI Global spa.

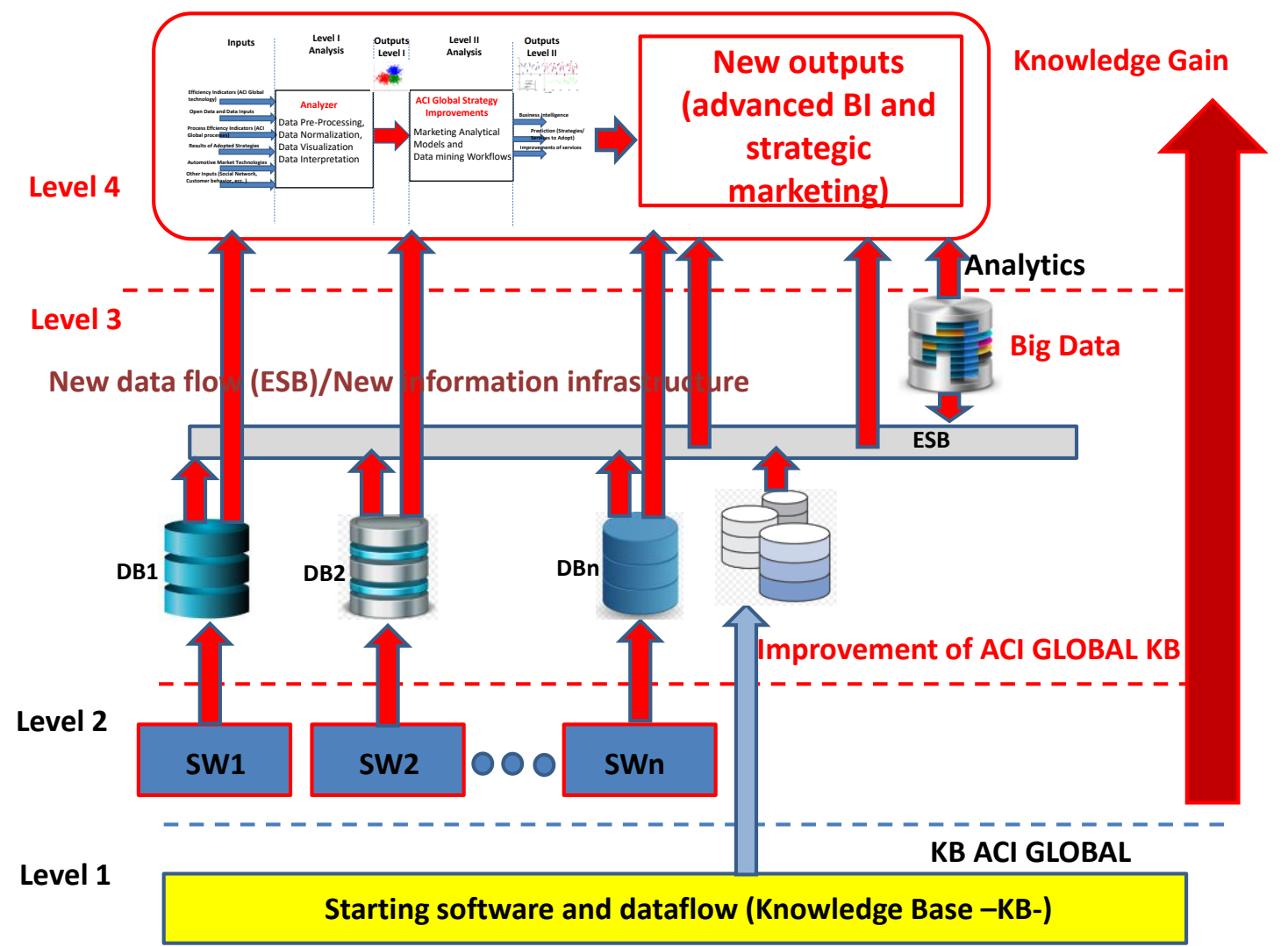

Figure 2. Knowledge Base Gain concept in ACI Global S.p.A. and four levels model upgrading KB (SW means software):data integration concept.

\section{Decision Making Concept and Examples of data Flow Automatisms}

The knowledge gain represented in Fig. 2 can be achieved by means of data processing of independent variables and of dependent variables. Specifically, gain factors $F$ can be reached by data mining processes (level 4 of Fig. 2), by means of automatism of the knowledge base (level 2 and 3 of Fig. 2), by management of database systems (level 3 of Fig. 2), and by customer data processing (level 2 and level 3 of Fig. 2). The decision making process and the marketing decisions can be the result of all the gain factors attainment: the BI goal can be achieved by processing all the dependent variables correlating the knowledge gain factors. An example of data automatism is represented by the Unified Modeling Language -UML- diagram of Fig. 4, involving different actors working for the quick assistance services (Pronto Assistance System -PAS-). The system is mainly characterized by the following features: 
- $\quad$ service for the insertion of the intervention via webservices;

- reading service of a specific intervention through webservices;

- service of reading a list of interventions through webservices;

- periodically executed clients for the notification to PAS of the most recent interventions;

- updating of the interventions (new fields in AS400 database systems);

- timeout status management for interventions.

\section{Knowledge Gain Factors F \\ (Independent Variables)}

\section{Goal}

(Dependent Variables)

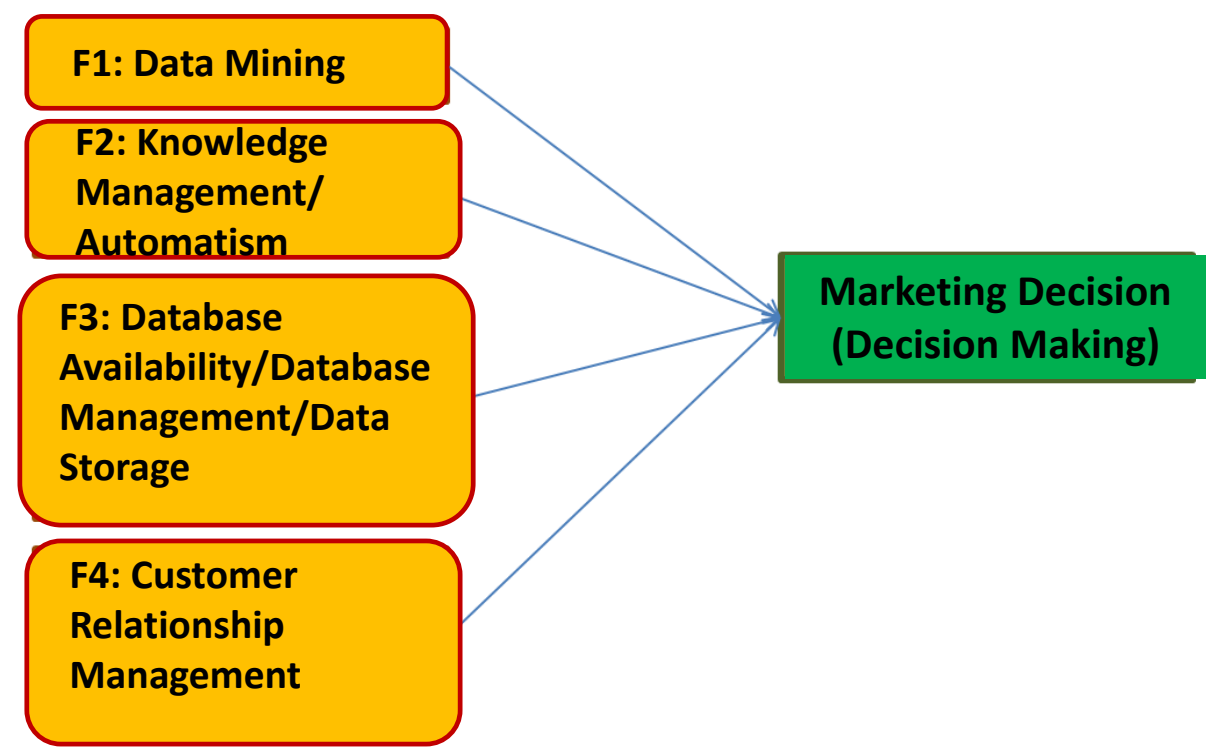

Figure 3. Knowledge gain factors Fi and BI/strategic marketing goal.

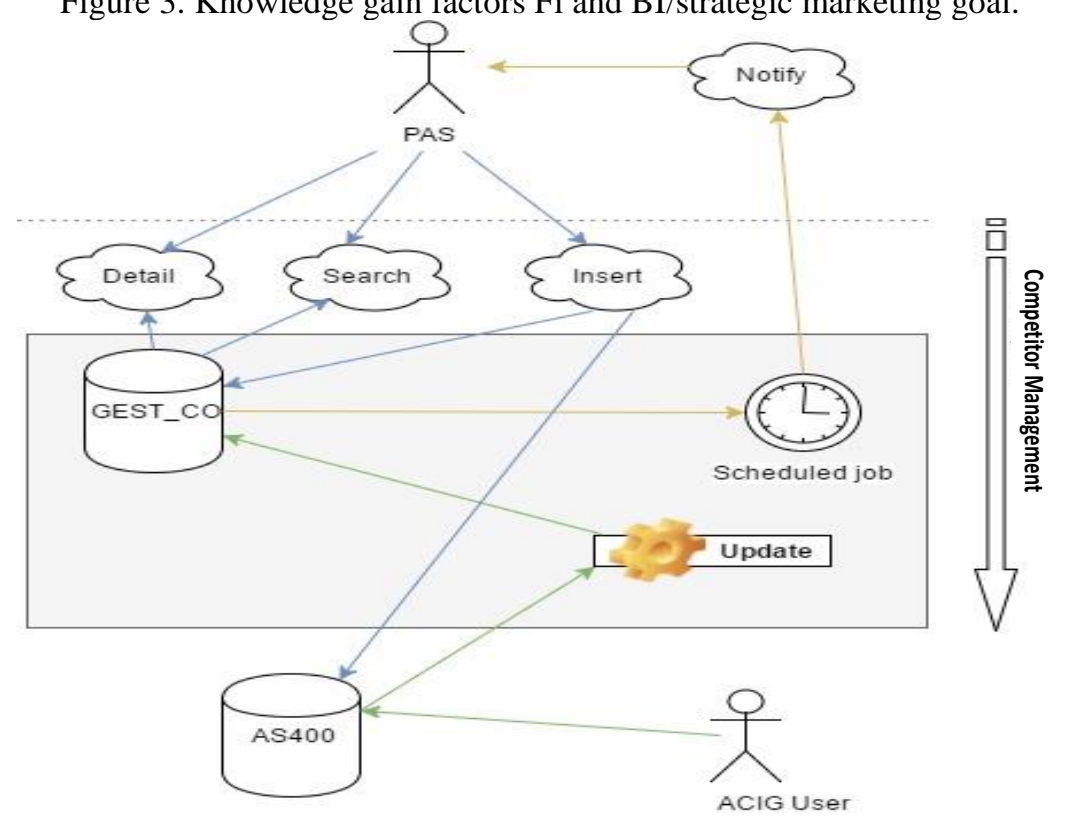

Figure 4. Architecture of competitor management model (level 2 and level 3 of Fig. 2, F2 factor of Fig.3). 
As other examples of data flow automatism, in Fig. 5 and Fig. 6 are illustrated the UML sequence diagram and the state diagram of the practice automated process improved into the industry information system ,respectively. In table 1 are listed the functions illustrated in Fig. 6 describing the data flow process.

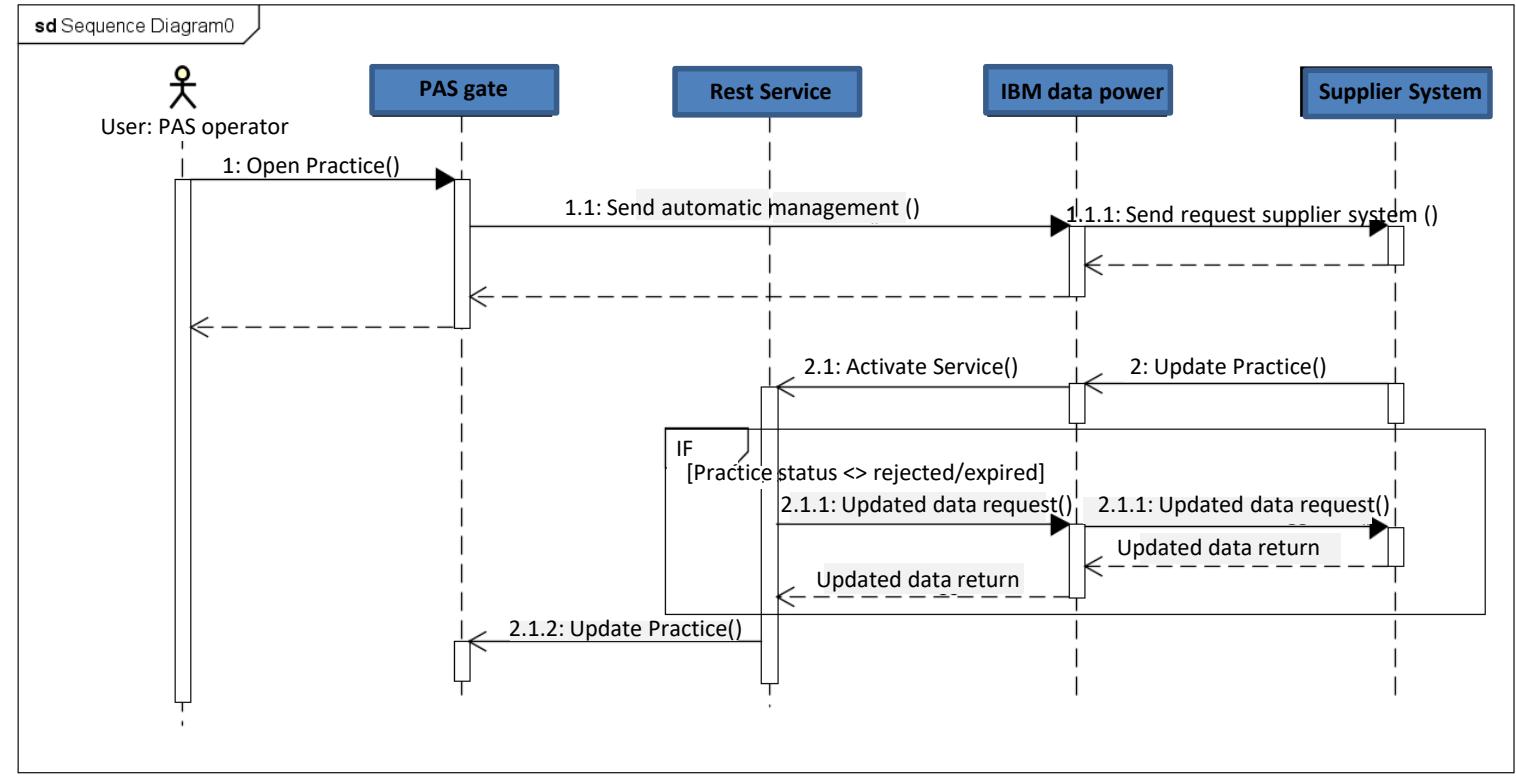

Figure 5. UML sequence diagram related the practice automatism.

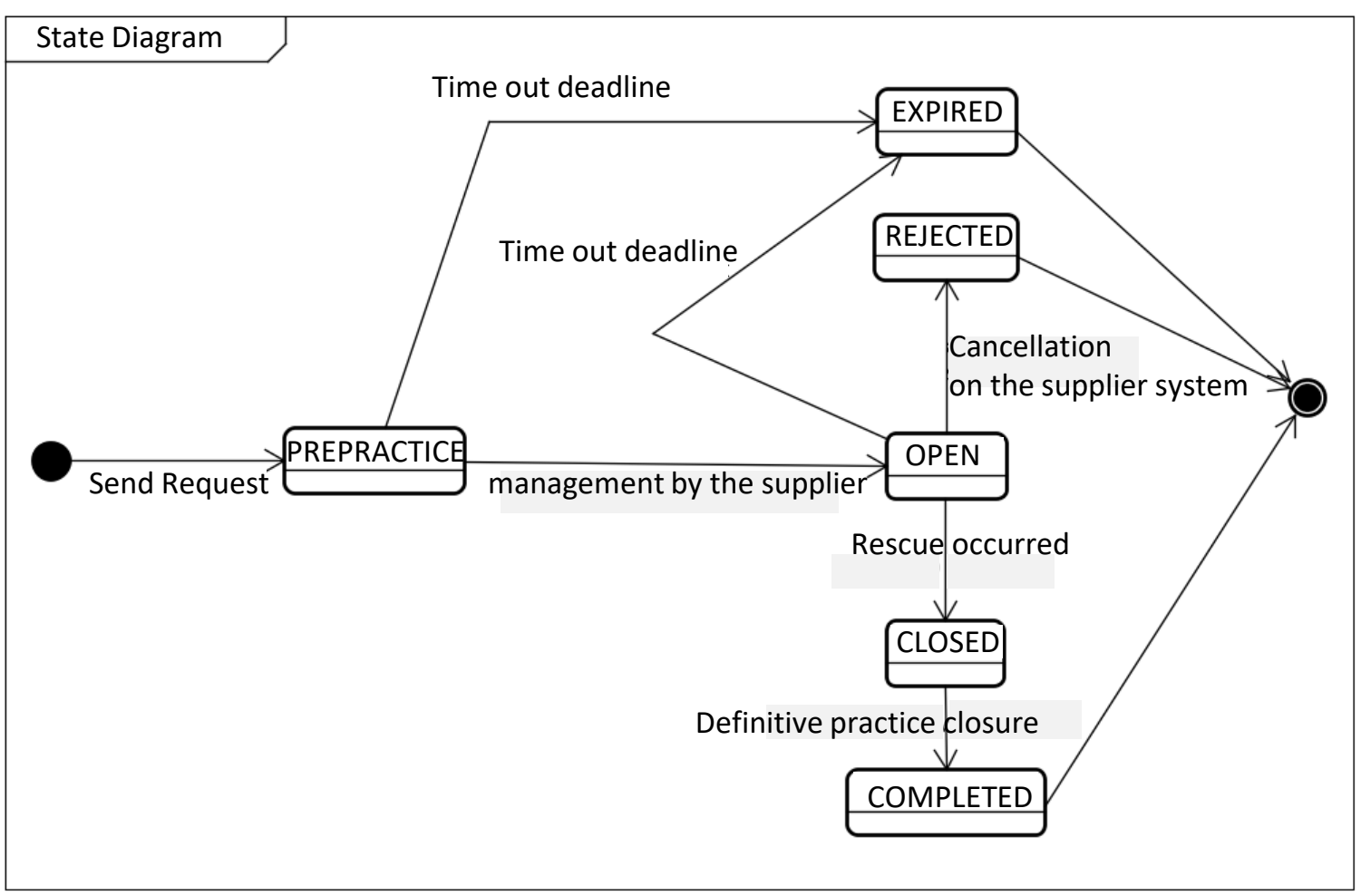

Figure 6. UML state diagram of the practice status. 
Table 1. Practice status illustrated in Fig.6.

\begin{tabular}{|l|l|l|}
\hline \multicolumn{1}{|c|}{ PAS gate status } & \multicolumn{1}{|c|}{ Description } & \multicolumn{1}{c|}{ Output status } \\
\hline PRE-PRATICE & Sending the request & Taking charge \\
\hline OPEN & $\begin{array}{l}\text { The practice is taken in charge by the Supplier. } \\
\text { Data returned by the supplier: possible updates of } \\
\text { locations, intervention times and place of } \\
\text { destination. }\end{array}$ & Taking charge \\
\hline EXPIRED & $\begin{array}{l}\text { The practice is not managed within the established } \\
\text { time out }\end{array}$ & Timeout \\
\hline REJECTED & The practice is canceled on the supplier's system & Cancelled \\
\hline CLOSED & $\begin{array}{l}\text { The rescue vehicle unloaded the vehicle at the } \\
\text { first destination (rescue occurred). } \\
\text { Data returned by the supplier: } \\
\text { detention location, intervention times and first } \\
\text { final destination. }\end{array}$ & Closed \\
\hline COMPLETED & $\begin{array}{l}\text { The mission is available for the acceptance or for } \\
\text { contestation of mission costs. } \\
\text { Data returned by the supplier (all destinations } \\
\text { including the last one and mission costs). }\end{array}$ & Managed \\
\hline
\end{tabular}

The decision making processes and the data flow automatism support the industry performance and the BI.

\section{Multilevel analytics Model (MAM)}

In this section is discussed how the decision making can be performed by the MAM model of Fig. 1 by proposing different applications and data processing involving different variables. The dataset used for the MAM model of paragraph 4.1 and 4.2 is hypothetical: according to car services structured into central services and external services has been created a dataset reproducing an hypothetical trend of amount of services. The dataset of paragraph 4.3 is extracted by real data found in ANIASA open data [27].

\subsection{Analyzer Module (analytics level 1)}

A first level of decision making process can be performed by the analyzer module. By using the Rapid Miner graphical user interface -GUI- it is possible to filter and pre-process data by neglecting empty fields, by adding values or by managing columns and rows of the dataset to process. In this way it is possible to process the data related to a specific process thus optimizing the statistic analytics, and focusing the attention on specific variables. In Fig. 7 are illustrated two cases of workflows allowing level 1 analytics by means of Rapid Miner dashboards. In the proposed example the analyzer module plots simulated amounts (variable "IMPORTO") versus the months, allowing to analyze the amount trend during the time (see output of Fig. 8). 


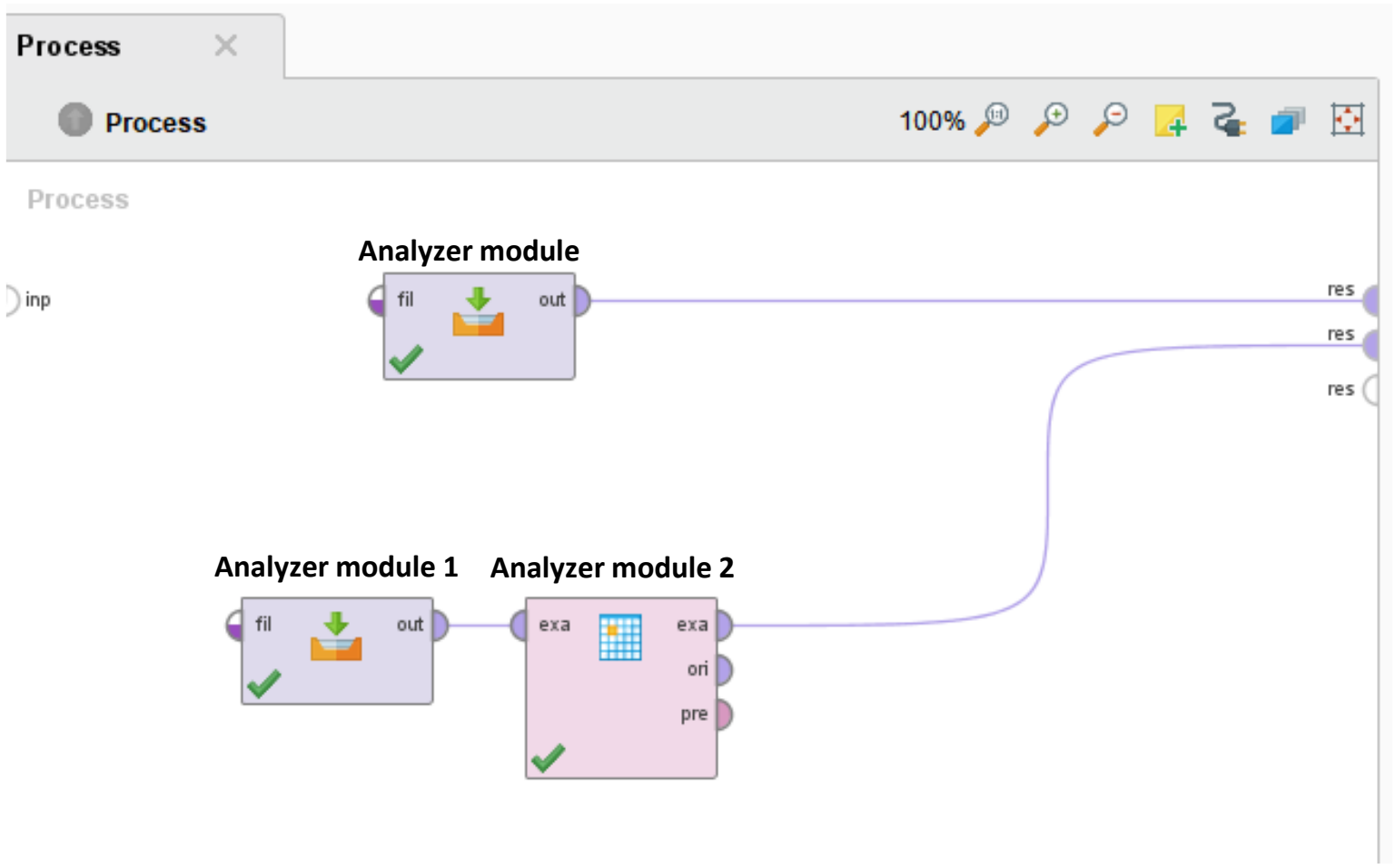

Figure 7. Rapid Miner workflow: analyser module workflow configurations (level 1 analytics).
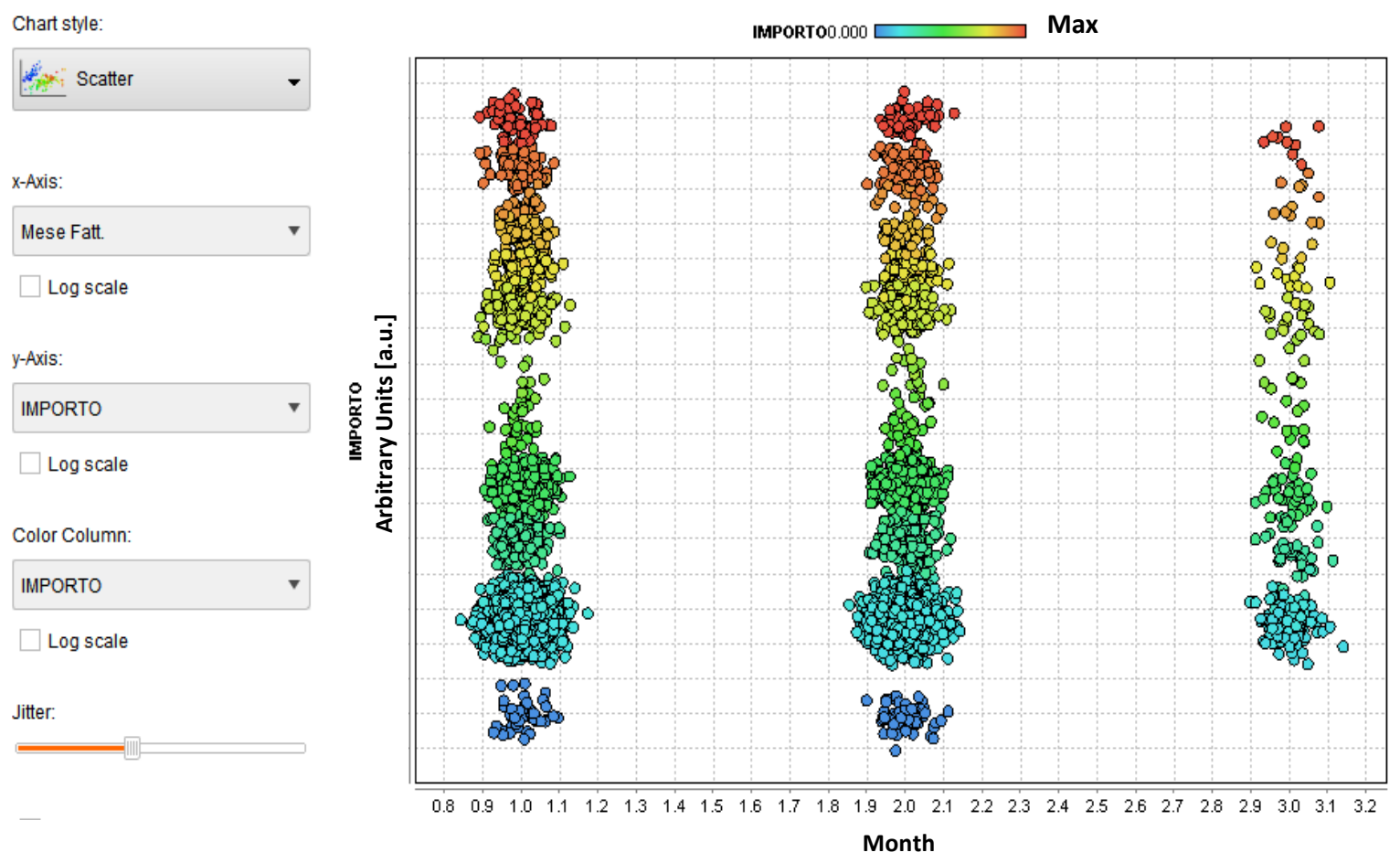

Figure 8. Rapid Miner 'Scatter' dashboard: graphical dashboard illustrating simulation results about amount trend versus month variable. 


\subsection{Module 2 (analytics level 2)}

In order to perform a precise analysis, data should be cleaned, filtered or pre-processed by the analyzer module, and, successively, processed by the second module executing data mining algorithms. This data process is representative of the MAM model which is simplified by the Rapid Miner workflows of Fig. 9 (a) and Fig. 9 (b), where simulation data filtered by the module 1 are processed by a k-means clustering algorithm (module 2 ).

(a)

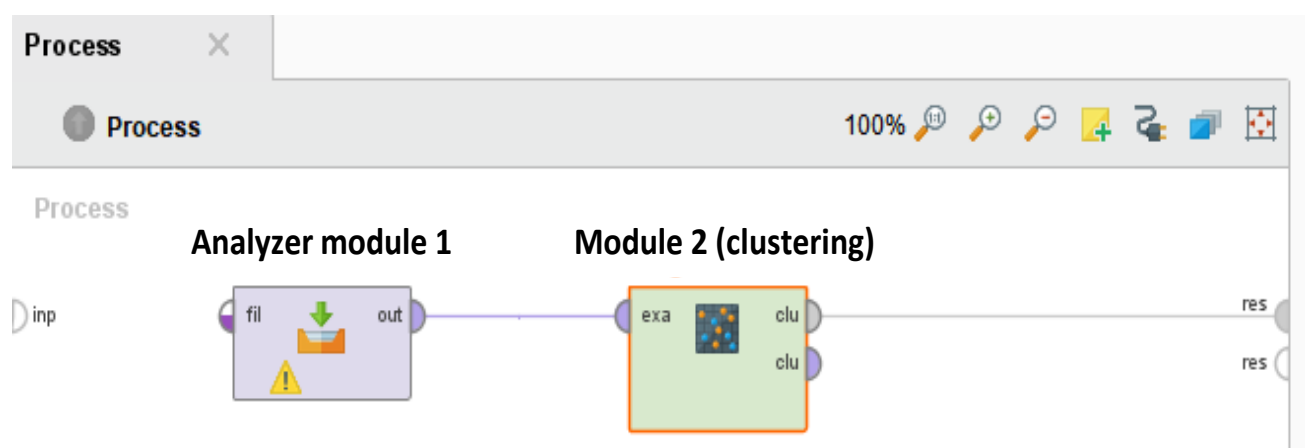

(b)

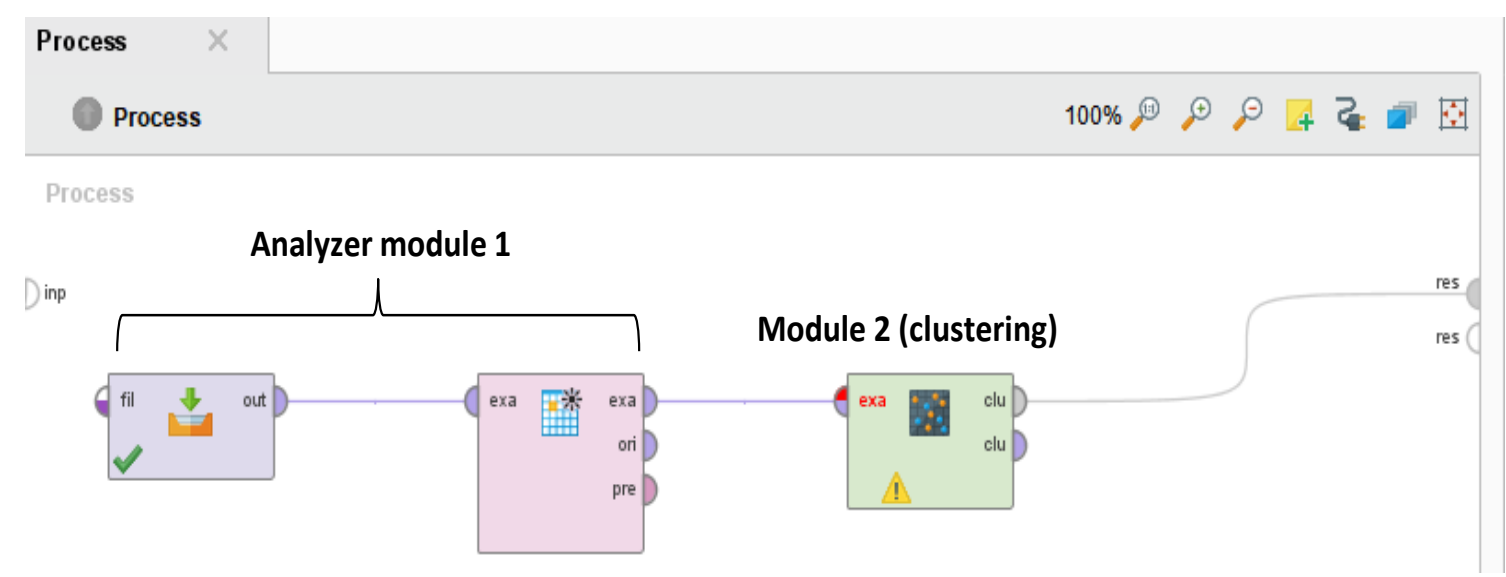

Figure 9. (a),(b) Rapid Miner workflow interconnecting module 1 (level 1 analytics) and module 2 (level 2 analytics): MAM model basic workflow layout.

The workflow outputs of Fig. 10 illustrate the K-Means clusters $(\mathrm{K}=3)$ by analysing the simulated variables "IMPORTO" (amount of external services) and "IMPORTO CENTRALE" (amount regarding central services). 

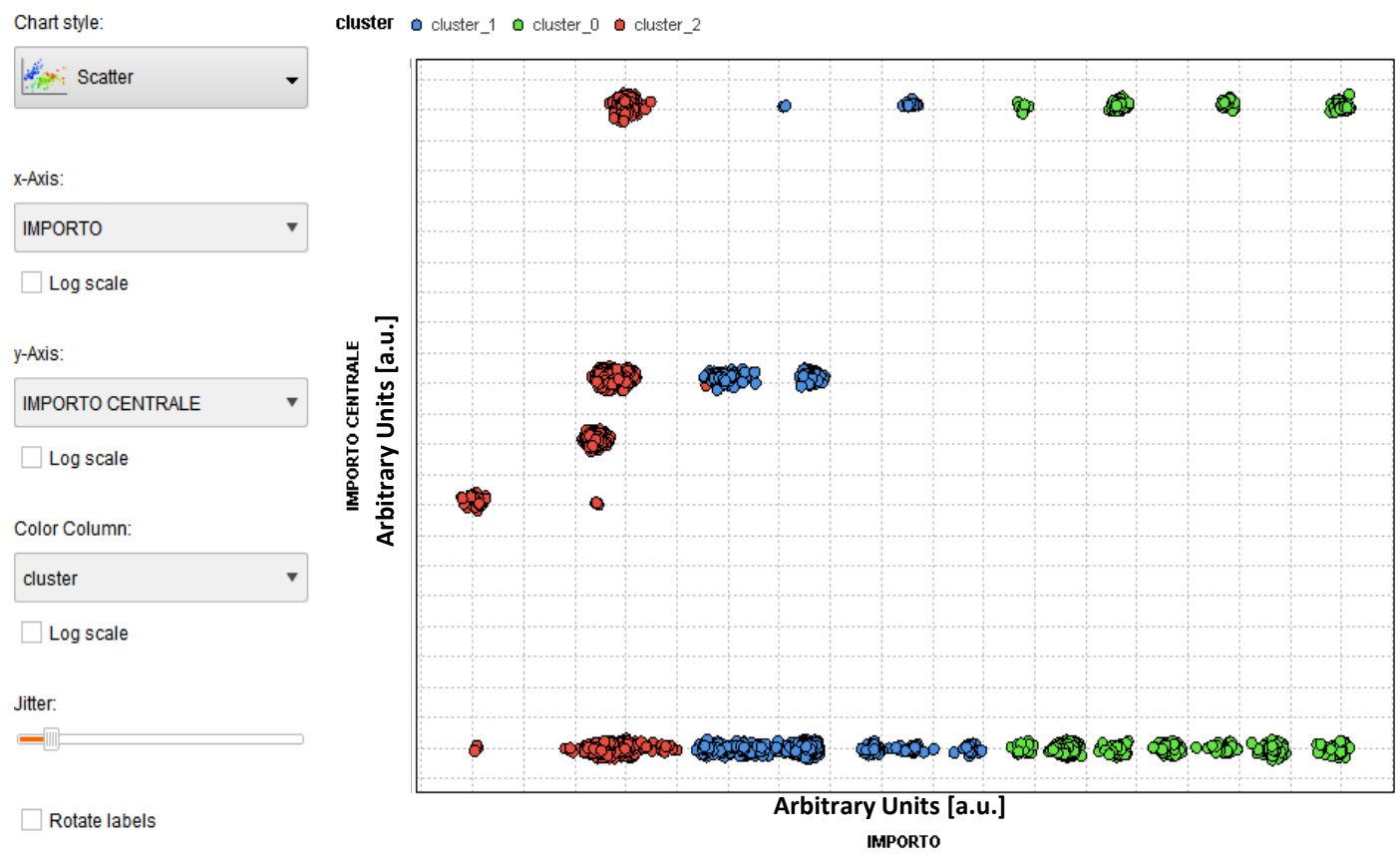

Figure 10. Clustering results of the K-Means algorithm.

In Fig. 10 is shown a first cluster (cluster_2) related to lower amounts, a second one associated with medium amounts (cluster_1), and a third one of higher amounts. The plot of Fig. 11 provides more information about the amount distribution of Fig. 10: in Fig. 11 are distinguished better the clusters by showing how the main service activities are mainly unrelated from the generic ones (only the cluster_2 groups aggregates similar features of services).
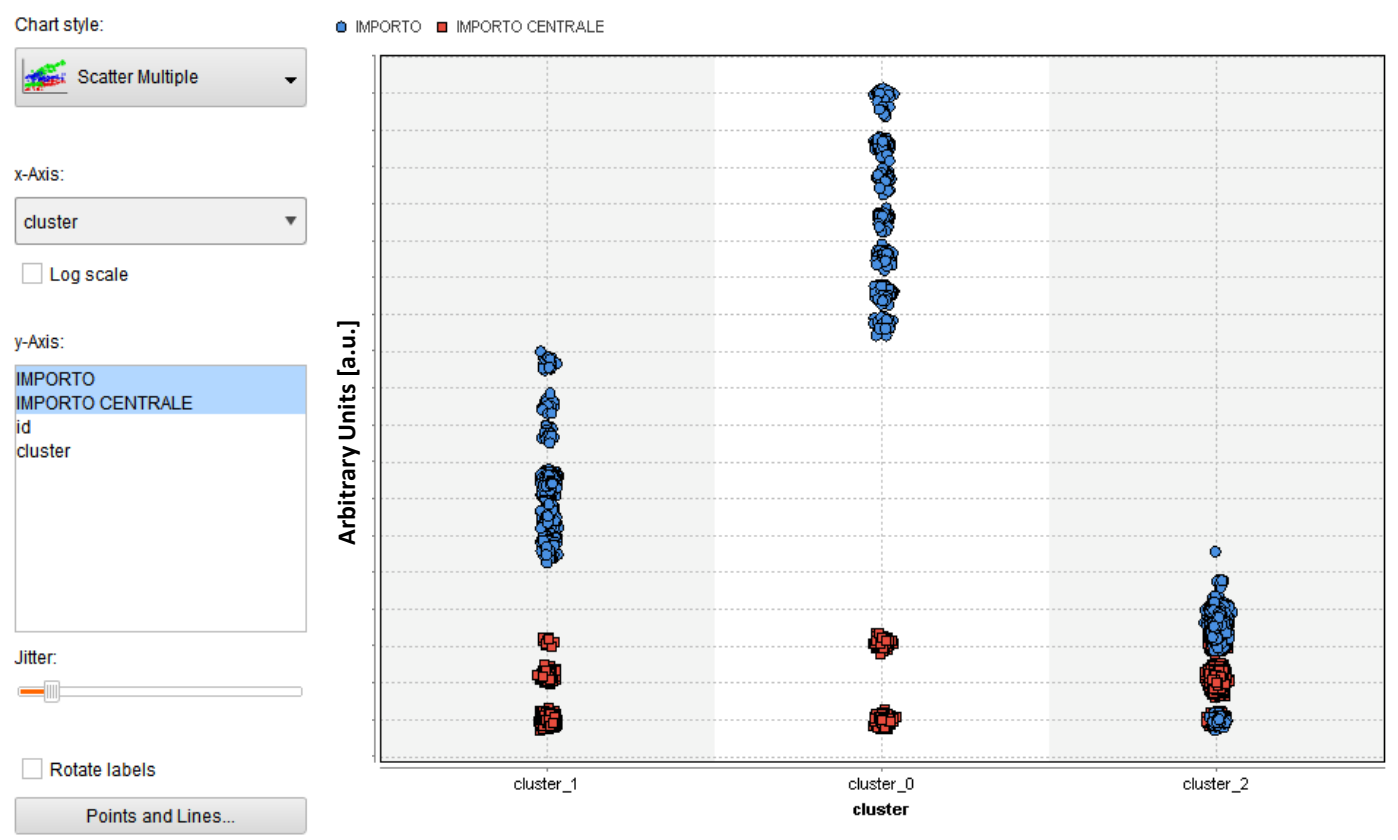

Figure 11. Clustering results of the K-Means algorithm.

The examples of Fig.10 and Fig. 11 enhance how it is possible to analyse the same output by different point of view simply by considering different dashboards. 


\subsection{Advanced Analytical model: accidents and car sharing models}

Following 'Frascati' theory the MAM model has been implemented involving researchers and analysts in the economy sector of car services. In Fig. 12 is illustrated the same model of Fig.1 matched with the methodological approach based on the application of an analytical model.

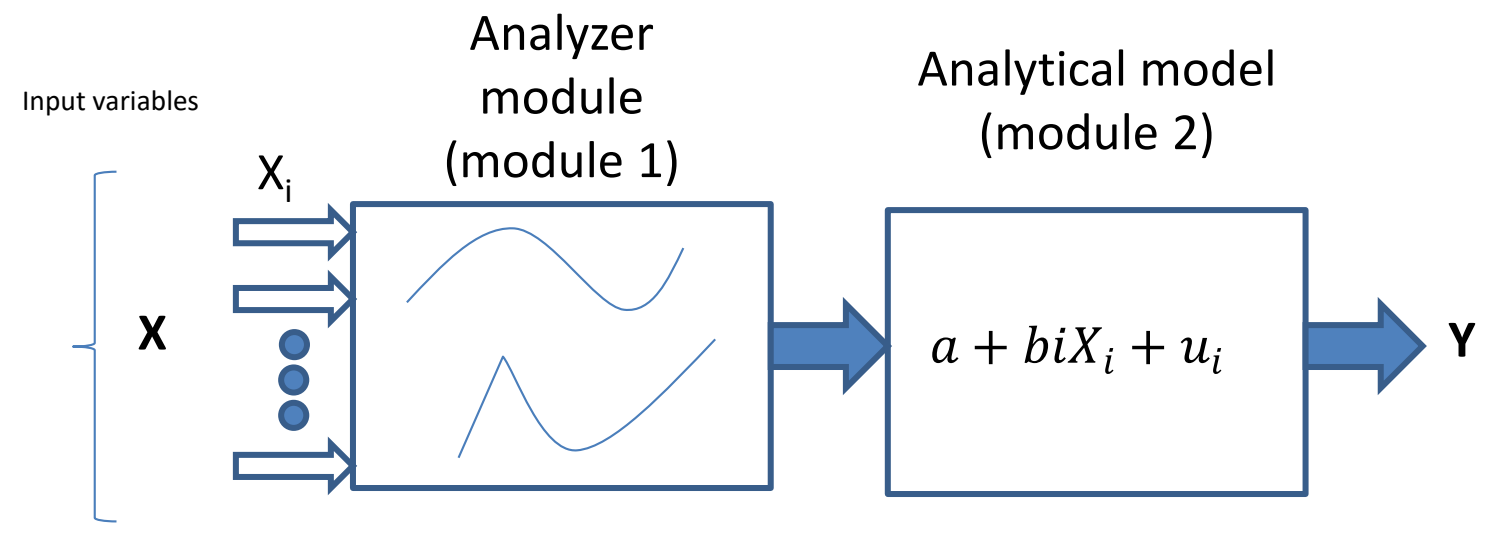

Figure 12. MAM model applied to analytical model.

The analytical model is modeled by the following generic equation:

$$
Y_{i}=a+b i X_{i}+u_{i}
$$

where $a$ is a constant representing the intersection with the y-axis, bi are the angular coefficients provided by the regression line, $X_{\mathrm{i}}$ are the input variables, $Y$ is the model output, and the pedix $i$ represents the geolocalization.

\subsubsection{Vehicle accident model}

The vehicle accidents phenomena in Italy (ANIASA open data [27]) are important to understand the rescue service evolution trend. The model which estimates the accidents origin is performed by defining the following input variables:

- Total_Car_Number: number of cars used in Italy;

- Population_Age: age of drivers;

- Eductation_Title: education title of drivers;

- PovertyIndex: generic index of poverty of Italian population;

- GenderDiversification: a measure of gender discrimination;

- GiniIndex: a measure of income inequality;

- Transport_regulations: binary value of dummy variables.

The model is provided by the following equation:

$$
\begin{aligned}
Y i=\text { Accident } & \\
& =a+b_{1}(\text { Total_Car_Number })_{i}+b_{2}(\text { Population_Age })_{i} \\
& +b_{3}(\text { Education_Title })_{i}+b_{4}(\text { PovertyIndex })_{i} \\
& +b_{5}(\text { GenderDiversification })_{i}+b_{6}(\text { GiniIndex })_{i} \\
& +b_{7}(\text { Transport_Regulations })_{i}+u_{i}
\end{aligned}
$$


By defining the following input variables it is possible to obtain the regression line of the probability of accidents (PrAccidents) and of the accident discrimination (AccidentDiscrimination):

DriverData: grouping data about demography regarding drivers;

Demography: grouping data about whole Italian population;

Sociality: quality of social life;

PublicTransport: presence of public transport (train, bus, etc.);

TransportPublicExpenditure: total expenditure of public transport;

TotalAccidentNumber: total number of accidents;

Mortal_Accidents: total number of mortal accidents;

Deads: number of deads in accidents;

Wounded: number of wounded in accidents.

The models processing the above listed variables are described by equation 3 and equation (4).

$$
\begin{aligned}
& Y_{i}=\text { PrAccidents }_{i}=a+b_{1}\left(\text { Driver_Data }_{i}+b_{2}\left(\text { Demography }_{i}+\right.\right. \\
& b_{3}(\text { Sociality })+b_{4}(\text { PublicTransport })_{i}+ \\
& b_{5}(\text { TransportPublicExpenditure })_{i}+u_{i}
\end{aligned}
$$

$$
\begin{aligned}
& Y_{i}=\text { AccidentDiscrimination }= \\
& a+b_{1}(\text { Total_Accident_Number })+b_{2}(\text { Mortal_Accidents })+b_{3}(\text { Deads })+ \\
& b_{4}(\text { Wounded })+c
\end{aligned}
$$

The probability of accidents and the accident discrimination can impact on services number and on service classifications (rescue services). The analytical model shows that the number of rescue service can increase with the total number of vehicles.

\subsubsection{Fleet car sharing model}

In this section are described the analytical model concerning car sharing. The theoretical model executes the following independent variables $\left(X_{\mathrm{i}}\right)$ :

LocalDemand: demand in the city of the car sharing service

PollutionReduction: pollution reduction due to the reduction of travelling vehicles;

CongestionReduction: reduction of traffic congestion;

GeneralMobility: optimization of general mobility.

MarketEconomy: profit area of car sharing firms;

PublicEconomy: public firms working in car sharing;

PublicGoods: public goods characterized by absence of rivalry and positive externalities;

Cooperation: not for profits firms;

NegativeExternalitiesResuction: reduction in negative externalities associated with reduction in pollution;

ReductionofLegalDisputeCost: reduction of legal dispute due to a more law coherent drivers behavior;

PublicExpenditureReductionForIncentives: reduction of individual incentives devoted to change driver behavior;

SocialCapitalCreation: increasing in the level of human capital and civil behavior of drivers;

RelationalCapital: developing relationships among citizens and drivers; 
ConfidenceCreation: level increasing of confidence about mobility;

ProfitsFleets: car sharing profits for fleets (Euro as money units);

AverageRentalPrice: average price for a rent (see Fig. 13 indicating a decrease associated with an increase of rental number);

RentalAverageDuration: average duration of a rent;

RentalDays: total number of days for fleet rent;

AverageFleetUse\%: value expressed in percentage of the average use of the shared fleet;

Employees: number of employees related to the industries working in car sharing (see Fig. 14 indicating a reduction of employees number associated with an increase of average rental price);

RentalNumber: total number of car rentals;

AveragePriceRentalDays: average price for a fleet rental day.

The model providing the car sharing values is performed by:

$$
\begin{aligned}
& Y_{\mathrm{i}}=\text { CarSharingValue }= \\
& a_{1}+b_{1}(\text { LocalDemand })+b_{2}(\text { PollutionReduction })+ \\
& b_{3}(\text { CongestionReduction })+b_{4}(\text { GeneralMobility })
\end{aligned}
$$

This model could provide useful information about a strategic marketing about car sharing service. The analytical model describing the market structure embedding car sharing is provided by:

$$
\begin{aligned}
& Y_{i}=\text { CarSharingEconomics }= \\
& a_{1}+b_{1}(\text { MarketEconomy })+b_{2}(\text { PublicEconomy })+b_{3}(\text { Cooperation })
\end{aligned}
$$

The market structure is important to understand to rule of profits firms, public institutions and not profit organizations (generic market structure). The following model delivers the specific rule of the public component in the market structure:

$$
\begin{aligned}
& Y_{i}=\text { PublicCarSharingEconomics }= \\
& a_{1}+b_{1}(\text { PublicGoods })+b_{2}(\text { NegativeExternalitiesReduction })+ \\
& b_{3}(\text { ReductionOfLegalDisputeCost })+ \\
& b_{4}(\text { PublicExpenditureReductionForIncentives })+ \\
& b_{5}(\text { SocialCapitalCreation })+b_{6}(\text { RelationalCapital })+ \\
& b_{7}(\text { ConfidenceCreation })
\end{aligned}
$$

This specific rule can be important in the case where public organizations invests in car sharing The car sharing profits model of the private sector is expressed by:

$$
\begin{aligned}
& Y_{i}=\text { ProfitsFleets }= \\
& a_{1}+b_{1}(\text { AverageRentalPrice })+b_{2}(\text { RentalAverageDuration })+ \\
& b_{3}(\text { RentalDays })+b_{4}(\text { AverageFleetUse } \%)+b_{5}(\text { Employees })
\end{aligned}
$$

A specific car service can be performed by considering fleet management and fleet rental. A marketing index suitable for fleet service can be the estimation of car sharing rental days. The car sharing rental days for fleet is estimated by:

$$
\begin{aligned}
& Y_{\mathrm{i}}=\text { RentalDays }= \\
& a_{1}+b_{1}(\text { ProfitsFleets })+b_{2}(\text { RentalNumber })+ \\
& b_{3}(\text { RentalAverageDuration })+b_{4}(\text { AveragePriceRentalDays })+ \\
& b_{5}(\text { AverageFleetUse } \%)+b_{6}(\text { Employees })
\end{aligned}
$$


International Journal on Soft Computing, Artificial Intelligence and Applications (IJSCAI), Vol.8, No.1, February 2019

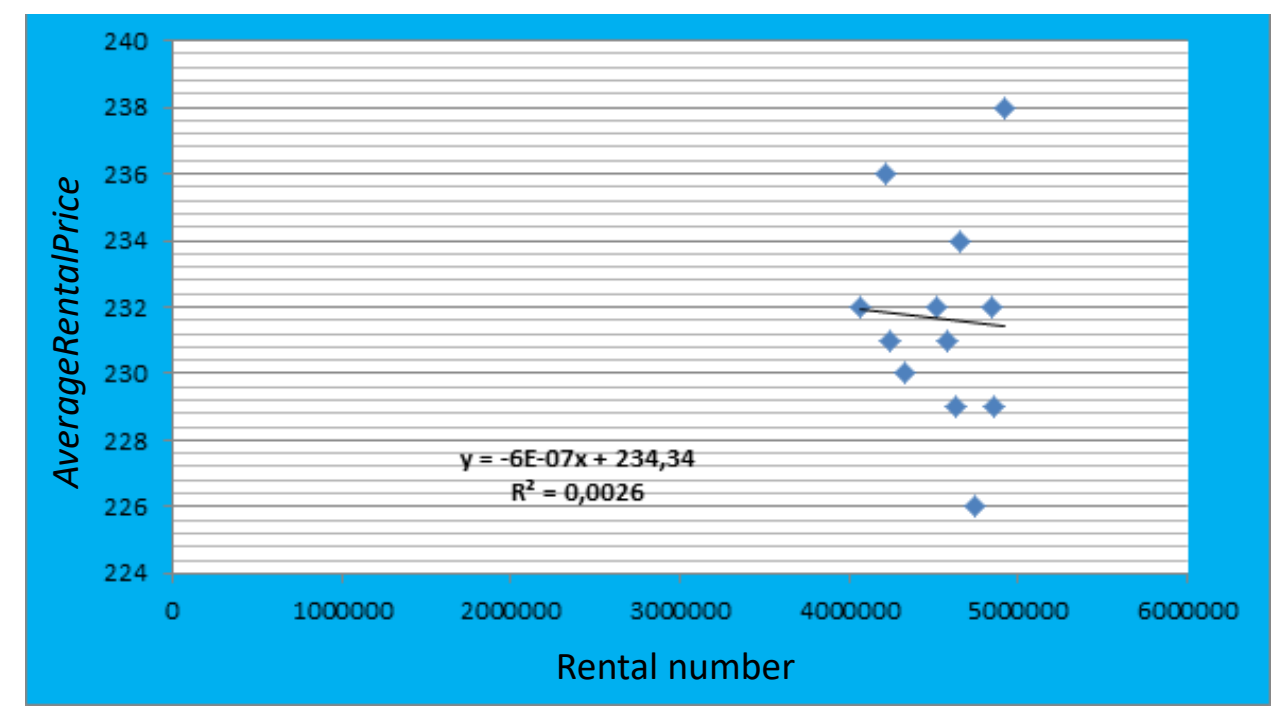

Figure 13. Module 1 output: AverageRentalPrice trend respect to rental number.

where:

$$
\begin{aligned}
& \text { AverageFleetUse } \% \\
& =a_{1}+b_{1} \text { (Employees) }+b_{2} \text { (Profits) } \\
& +b_{3} \text { (RentalDays) } \\
& +b_{4} \text { (AveragePriceRentalDays) } \\
& =a_{1}+b_{1} \text { (Profit) }+b_{2} \text { (AverageRentalPrice) } \\
& \left.+b_{3} \text { (RentalAverageDuration }\right)+b_{4} \text { (RentalDays) } \\
& \left.+b_{5} \text { (AverageFleetUse } \%\right)
\end{aligned}
$$

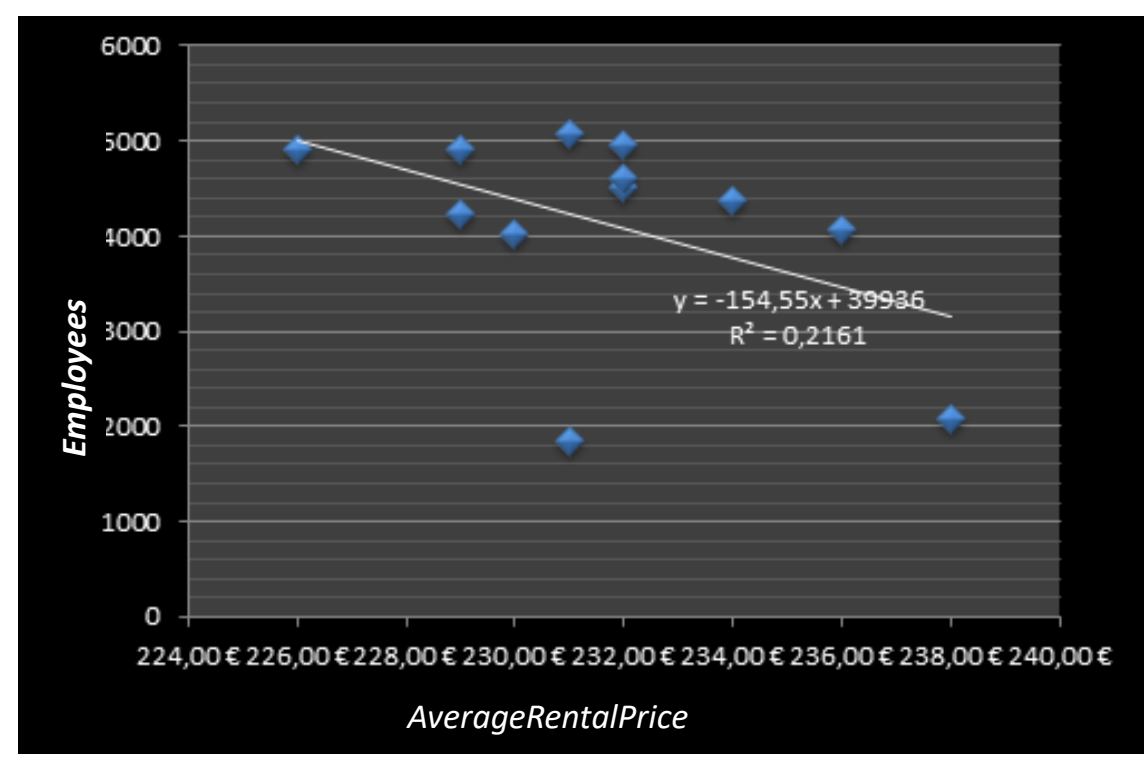

Figure 14. Module 1 output: Employees trend respect to AverageRentalPrice variable. 
In Fig. 15 is illustrated as example the linear regression output of the model Yi=ProfitFleets: an increase trend is estimated thus conforming that investments in car sharing of fleet are strategic.

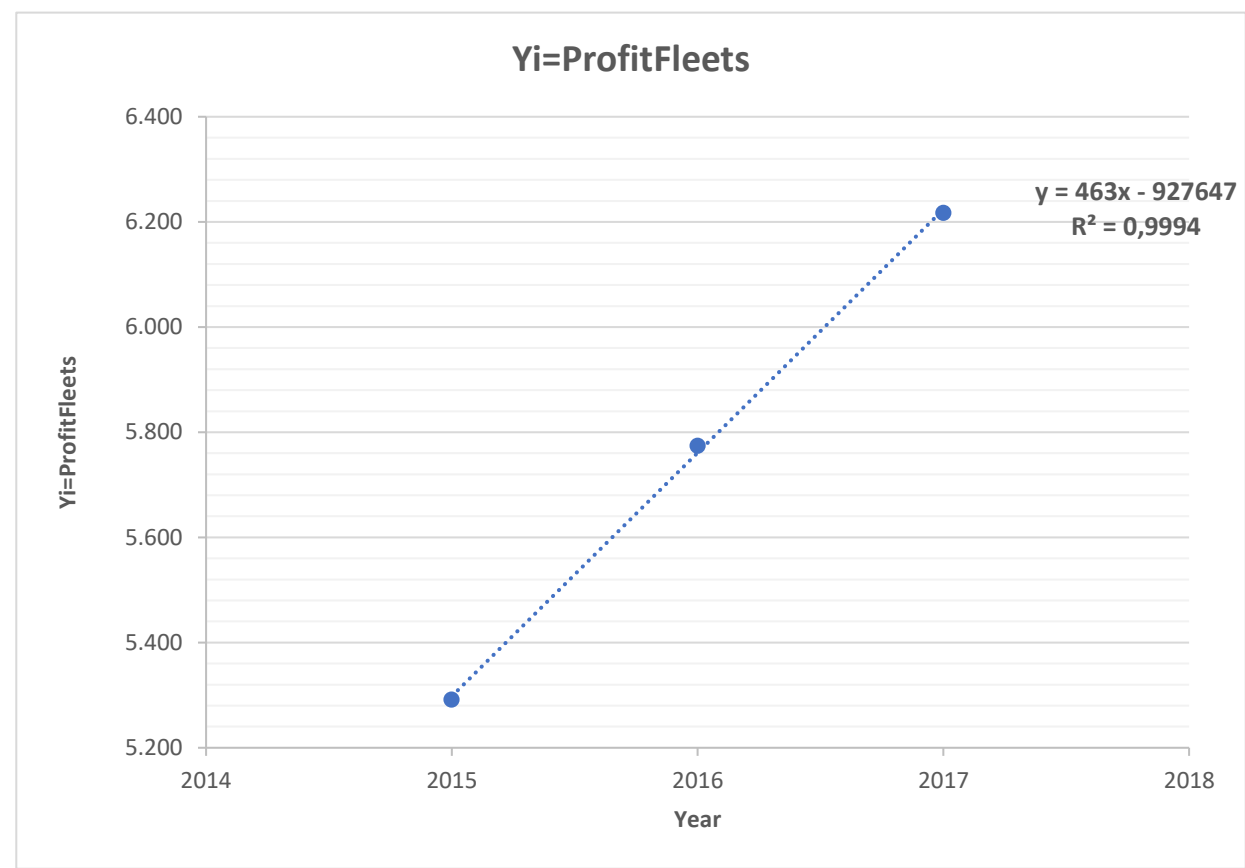

Figure 15. Module 2 output: ProfitFleets trends versus the year.

\subsubsection{Car sharing model: correlation matrix approach}

In order to understand how the variables are correlated has been executed the correlation matrix algorithm. In Fig. 16 is illustrated a second example of MAM model embedding the 'Correlation Matrix module' (module 2 related to an algorithm which calculates the Pearson's correlation coefficient [28]-[29]). Figure 17 shows the correlation results enhancing relationships between variables adopted for the calculus of the ProfitFleets. The Correlation Matrix allows to perform a deeply analysis of the analytical model finding groups of correlated variables having a major weight (see red color up and down the diagonal), and variables having a negative correlation (see Employee variable thus indicating that an increase of Employee value provides a partial decrease of the ProfitFleets).

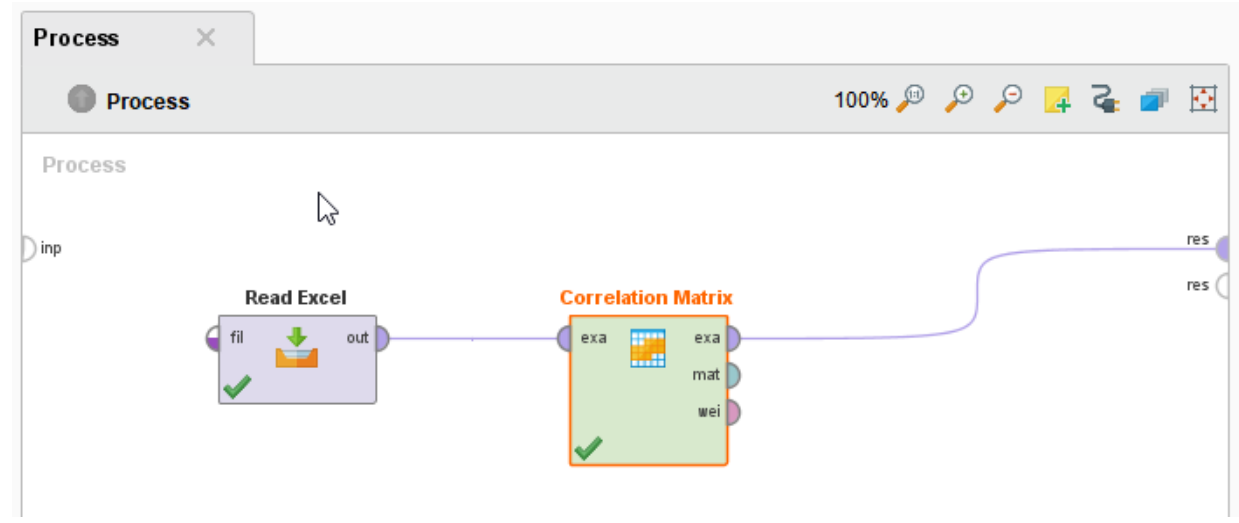

Figure 16. MAM model implementing Correlation Matrix algorithm. 


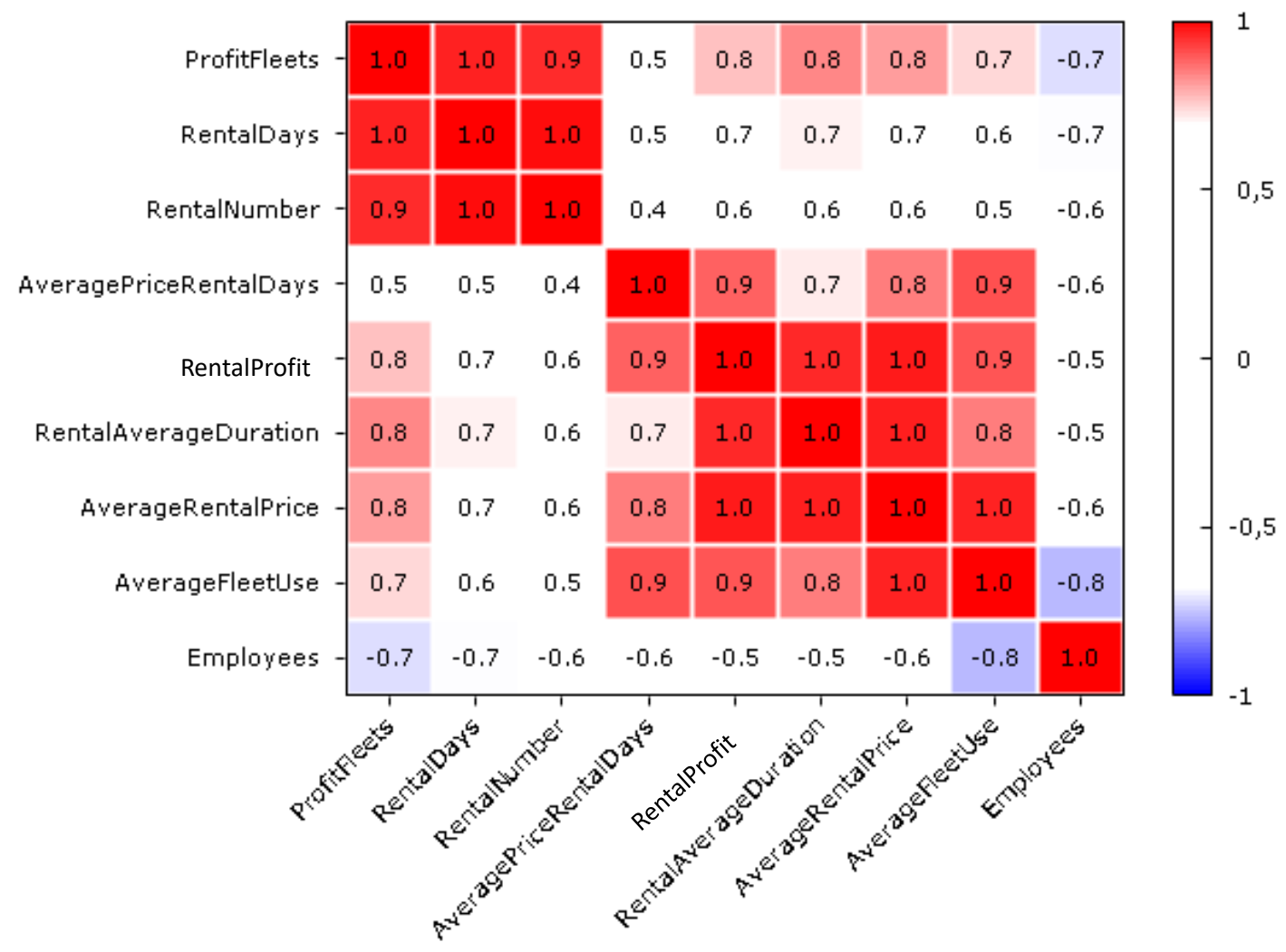

\section{CONCLuSiON}

Figure 17. Module 2: correlation Matrix output.

The paper proposes a methodology able to improve a BI model embedded into an information system of an industry working in car services. The model and the adopted research can be generalized for other industry sectors. Following 'Frascati' guidelines are discussed some facilities generating decision making such as data flow automatism and advanced analytical models. The work is focused on the implementation of the multilevel analytics model -MAM- characterized by two levels of analytics stages: the first one is related to the analysis of each single variable (module 1 ), and the second one is related of an advanced analysis performed by data mining and analytical models (module 2). For data mining has been applied the K-Means algorithms useful in the case of study for the clustering of the amounts of services. Concerning analytical models, the MAM has been applied also for the analysis the vehicle accident cases, and for the economics of car sharing and fleet sharing evolution and management, by processing open data and correlations between variables. According with simulation results external service could be important for industry strategy. Furthermore, by comparing accidents and fleet car sharing trends it is possible to improve BI strategies by focusing the attention on these services. In order to increase profits in fleet car sharing it is important to control the Employee value: correlation matrix provides an inversely proportional behaviour between Employee and ProfitFleets variables. The proposed analytical approaches are useful in order to simulate a BI strategies reading MAM model outputs. The MAM model is suitable for strategic marketing, and can be applied to different variables and data provided by the upgraded information system of Fig. 2. The results commented in this paper are a part of results obtained by the development of different joint projects. 


\section{ACKNOWLEDGEMENTS}

The work has been developed in the frameworks of the Italian projects: "Modello di analisi a due livelli per l'ottimizzazione dei servizi ACI e la pianificazione di business intelligence "ACI B.I. Level Strategic Marketing'" [Two-level analysis model for the optimization of ACI services and business intelligence planning 'ACI B.I. Level Strategic Marketing']. The authors would like to thank the following researchers and collaborators: G. Birardi, B. Boussahel, V. Calati, D. Carella, A. Colonna, R. Cosmo, V. Custodero, L. D’Alessandro, G. Fanelli, R. Guglielmi, M. Legrottaglie, A. Lombardi, G. Lonigro, A. Lorusso, L. Maffei, S. Maggio, N. Malfettone, D. Mangini, V. Maritati, S. F. Massari, G. Meuli, L. Pellicani, R. Porfido, D. D. Romagno, G. Ronchi, P. Scagliusi, S. Selicato, G. Sicolo, M. Solazzo, M. M. Sorbo, D. Suma, F. Tarulli, E. Valenzano and V. Vitti.

\section{REFERENCES}

[1] Poletti, E. (2005) "Analisi dei costi nel settore automobilistico", thesis. [Online]. Available: http://tesi.cab.unipd.it/306/1/poletti.pdf

[2] Pedron, A. (2004) "Possibilità di sviluppo del mercato delle auto elettriche tramite il Battery Swapping”, thesis. [Online]. Available: http://dspace.unive.it/bitstream/handle/10579/4187/8163411168650.pdf?sequence $=2$

[3] Caprioglio, S. (2003) "La comunicazione sociale tra approccio comunicativo e di marketing", thesis. [Online]. Available: http://www.regione.piemonte.it/network/dwd/biblio/caprioglio.pdf

[4] Gentile, A. (2014) "Mobile Marketing: le app come strumento di comunicazione d'azienda nell'era del Mobile", thesis. [Onlione]. Available: https://amslaurea.unibo.it/8314/1/Gentile_Ada_tesi.pdf

[5] Pugna, I. B., Albescu, F. \& Babeanu, D. (2009), "The role of business intelligence in business performance management", Annals of Faculty of Economics, Vol. 4, No. 1, pp 1025-1029.

[6] Garrett, G. (2012) "How to create a Business Intelligence Strategy", Paper 021-2012, SAS Global Forum, pp 1-8.

[7] Olszak, C. M. \& Ziemba, E. (2007) "Approach to building and implementing business intelligence systems", Interdisciplinary Journal of Information, Knowledge, and Management, Vol. 2, pp 135-148.

[8] Wieder, B. \& Ossimitz, M. L. (2015) "The impact of business intelligence on the quality of decision making - a mediation model”, Procedia Computer Science, Vol. 64, pp 1163-1171.

[9] Fries, J. (2006) “The contribution of business intelligence to strategic management", thesis (Vrije Universiteit Brussel). [Online]. Available: http://www.ethesis.net/managment/managment.pdf

[10] Igbaekemen, G. O. (2014) "Marketing intelligence as a strategic tool for competitive edge", British Journal of Marketing Studies, Vol.2, No.5, pp 17-34.

[11] Sarangi, S. (2016) "Business intelligence systems: a necessity for agile supply chains", KIT Journal of Management, Vol.12, No. 2, pp 52-65.

[12] Kinholkar, S. A. \& Waghmare, K. C. (2016) "Enhance digital marketing using sentiment Analysis and end user behavior", International Research Journal of Engineering and Technology (IRJET), Vol. 03, No.7, pp 1083-1086.

[13] Skyrius, R., Katin, I., Kazimianec, M., Nemitko, S., Rumšas, G. \& Žilinskas, R. (2016) "Factors driving business intelligence culture”, Informing Science and Information Technology, Vol.. 13, pp 171-186. 
[14] Palade, H. C., Nicolaescu, S. S. \& Kifor, C. V. (2016) "Model of handling big data and knowledge management in automotive industry", Conference: Managing Innovation and Diversity in Knowledge Society Through Turbulent Time, pp 731-740.

[15] Bolton, A., Murray, M. \& Fluker, J., (2017) "Transforming the workplace: unified communications \& collaboration usage patterns in a large automotive manufacturer", Proceedings of the 50th Hawaii International Conference on System Sciences, pp 5470-5479.

[16] Goby, N., Brandt, T., Feuerriegel, S. \& Neumann, D. (2016) "Business intelligence for business processes: the case of it incident management", Proceeding of Twenty-Fourth European Conference on Information Systems, Istanbul, Turkey, ECIS 2016, pp. 1-15.

[17] Fernandez, D. D. \& Boissinot, A. (2014) "What leadership for the logistic service providers in the supply chain of the French automotive industry?", Working Paper 2014-172, Department of Research, Ipag Business School..

[18] Rezaein, A., Shokohyar, S. \& Zolfaghari, S. (2016) "Clustering and classification of road accidents in Iran using data mining techniques", International Journal of Business and Information, Vol. 11, No. 3, pp 365-383.

[19] Castro Y. \& Kim, Y. J. (2016) "Data mining on road safety: factor assessment on vehicle accidents using classification models", International Journal of Crashworthiness, Vol. 21, No. 2, pp 104 -111.

[20] Siddharth, A., Parneet, K. \& Prachi A., (2013) "Economical maintenance and replacement decision making in fleet management using data mining", The SIJ Transactions on Computer Science Engineering \& its Applications (CSEA), Vol. 1, No. 2, pp 37-48.

[21] Feth, P. \& Adler, R. (2016) "Service-based modeling of cyber-physical automotive systems: a classification of services", Workshop CARS 2016 - Critical Automotive applications Robustness.

[22] Massaro, A., Vitti, V., Galiano, A. \& Morelli, A. (2019) "Business intelligence improved by data mining algorithms and big data systems: an overview of different tools applied in industrial research", Computer Science and Information Technology, Vol. 7, No.1, pp 1-21.

[23] Frascati Manual (2015) "The measurement of scientific, technological and innovation activities guidelines for collecting and reporting data on research and experimental development", OECD (2015), ISBN 978-926423901-2 (PDF).

[24] Massaro, A., Maritati, V., Galiano, A., Birardi, V. \& Pellicani, L. (2018) "ESB platform integrating KNIME data mining tool oriented on Industry 4.0 based on artificial neural network predictive maintenance", International Journal of Artificial Intelligence and Applications (IJAIA), Vol.9, No.3, pp $1-17$.

[25] Massaro, A., Calicchio, A., Maritati, V., Galiano, A., Birardi, V., Pellicani, L., Gutierrez Millan, M., Dalla Tezza, B., Bianchi, M., Vertua, G., Puggioni, A. (2018) "A case study of innovation of an information communication system and upgrade of the knowledge base in industry by ESB, artificial intelligence, and big data system integration", International Journal of Artificial Intelligence and Applications (IJAIA), Vol. 9, No.5, pp 27-43.

[26] "WSO2" [Online]. Available: https://wso2.com/products/enterprise-service-bus/

[27] "ANIASA" [Online]. Avalable: https://www.aniasa.it/

[28] Massaro, A., Meuli, G. \& Galiano, A. (2018) "Intelligent electrical multi outlets controlled and activated by a data mining engine oriented to building electrical management", International Journal on Soft Computing, Artificial Intelligence and Applications (IJSCAI), Vol.7, No.4, pp 1-20. 
International Journal on Soft Computing, Artificial Intelligence and Applications (IJSCAI), Vol.8, No.1, February 2019

[29] Myers, J. L., Well, A. D. (2003) "Research Design and Statistical Analysis”, (2nd ed.) Lawrence Erlbaum. pp. 508, ISBN 0-8058-4037-0.

\section{Corresponding Author}

Alessandro Massaro: Research \& Development Chief of Dyrecta Lab s.r.l. 